\title{
REMOVAL OF ARSENIC FROM AQUEOUS SOLUTION BY PHOTOCATALYTIC UV IRRADIATION
}

\author{
Mahsa Jahangiri-rad, PhD Student \\ Department of environmental health engineering, Tehran medical sciences branch, \\ Islamic azad university, Tehran, Iran
}

\begin{abstract}
The purpose of this research was to investigate the photocatalytic removal of arsenic from aqueous solution using $\mathrm{UV} / \mathrm{TiO}_{2}$ process in a batch system. A $120 \mathrm{~W} \mathrm{UV} \mathrm{lamp} \mathrm{with}$ irradiation $247 \mathrm{~nm}$ wave lenght inside a quartz jacket was submerged in the reactor to provide better irradiation of water samples in the presence of $\mathrm{TiO}_{2}$ nanoparticles. The optimum dosage of $\mathrm{TiO}_{2}$ was obtained equal to $1 \mathrm{~g} / \mathrm{L}$, with variation $\mathrm{TiO}_{2}$ dosage at constant $\mathrm{pH}$ and initial concentrations of arsenic. The effect of $\mathrm{pH}$, contact time and initial concentration of arsenic was studied at the constant amount of $\mathrm{TiO}_{2}(1 \mathrm{~g} / \mathrm{L})$. The results showed that photocatalytic removal efficiency increased with increasing reaction time and $\mathrm{TiO}_{2}$ dosage. In addition, it was found that removal efficiency of arsenic decreased by increasing initial arsenic concentration and $\mathrm{pH}$. In conclusion the results showed that $\mathrm{UV} / \mathrm{TiO}_{2}$ was an effective method in removal of arsenic from aqueous solutions.
\end{abstract}

Keywords: $\mathrm{TiO}_{2}$ nanoparticles, arsenic, photocatalytic reaction, aqueous solution

\section{Introduction}

Arsenic is considered as one of the most toxic and carcinogenic elements (Basu et al., 2010). Arsenic compounds resemble in some respects those of phosphorus which occupies the same group (column) of the periodic table. Arsenic is less commonly observed in the pentavalent state, however. The most common oxidation states for arsenic are: -3 in the arsenides, such as alloy-like intermetallic compounds; and +3 in the arsenites, arsenics(III), and most organoarsenic compounds (Bellack, 1971). Arsenic occurs in natural water in organic and inorganic forms. The species of inorganic arsenic are dependent on the redox conditions and the $\mathrm{pH}$. Arsenic (As (V)) dominates in oxygen-rich waters and arsenite (As (III)) in reducing environments (Edwards, 1988). When heated in air, arsenic oxidizes to arsenic trioxide; the fumes from this reaction have an odor resembling garlic. Arsenic makes up about $1.5 \mathrm{ppm}$ of the Earth's crust. Soil contains 1-10 ppm of arsenic and Seawater has $1.6 \mathrm{ppb}$ arsenic. Minerals with the formula MAsS and $\mathrm{MAs}_{2}(\mathrm{M}=\underline{\mathrm{Fe}}, \underline{\mathrm{Ni}} \underline{\mathrm{Co}})$ are the dominant commercial sources of arsenic, together with realgar (an arsenic sulfide mineral) and native arsenic. Arsenic also occurs in various organic forms in the environment (Blssen and Frimmel, 2003). Many countries and districts in Southeast Asia, such as Vietnam and Cambodia , Western area of Iran (Kurdestan rural areas) and North Eastern and South Western coast area of Taiwan have geological environments conducive to generation of higharsenic groundwaters (Mandal and Suzuki, 2002). Widespread arsenic contamination of groundwater has led to a massive epidemic of arsenic poisoning. It is estimated that approximately 57 million people in the many parts of the world are drinking groundwater with arsenic concentrations elevated above the World Health Organization's standard of 10 parts per billion (ppb) (EPA, 2001). Due to such harmful effects of arsenic on human health, new USEPA regulation lowered the maximum contaminant level (MCL) for arsenic in 
drinking water from 50 to $10 \mu \mathrm{g} / \mathrm{L}$ (Sorg, 1997), therefore it is necessary to find novel technologies to access this new regulation. A large number of technologies have been examined to remove arsenic from contaminated water (Choong, Chuah, Robiah , Gregory,\& Azni, 2007). Many factors such as arsenic concentrations in water, presence of other constituents in water and expenses associated with a treatment process are contributed in selection of technology (Sorg, 1997). Arsenic removal methods include coagulation and precipitation (Chen and Wilkie, 1997), membrane separation (Choong et al., 2007), ion exchange (Waypa et al., 1997) and adsorption (Awual et al., 2008; B?aba et al., 1999). Many of the waste streams contain As(III), which requires oxidation before it can be removed by common methods such as iron co-precipitation or ion exchange. Since the oxidation rate of dissolved As(III) by oxygen is extremely slow, oxidants such as chlorine, ozone or permanganate need to be used. Chlorine has traditionally been the oxidant of choice, but there are growing concerns regarding the generation of organochloride byproducts from the naturally occurring organic matter which may also be present (EPA, 2001).In this paper Photocatalytic oxidation (PCO) was achieved with the combination of UV light rays and $\mathrm{TiO}_{2}$ nanoparticles. Nanoparticles have also solely known as effective adsorbents for some organic and inorganic substances. Therefor this paper evaluates the combination process of adsorption and advanced oxidation for arsenic removal. This process creates hydroxyl radicals and super-oxide ions, which are highly reactive electrons and designed to remove arsenic in water. The effects of other factors including Initial concentration of As(III), pH and light intensity were also investigated.

\section{Materials and methods}

$\mathrm{TiO}_{2}$ nano particles were purchased from Evonik-industrial company, Germany. The purity , especial surface area (BET) and sizes of the selected nanoparticles were $99.5 \%$, $50 \pm 15$ and $21 \mathrm{~nm}$, respectively. TEM image of selected $\mathrm{TiO}_{2}$ nanoparticles is shown in figue1.

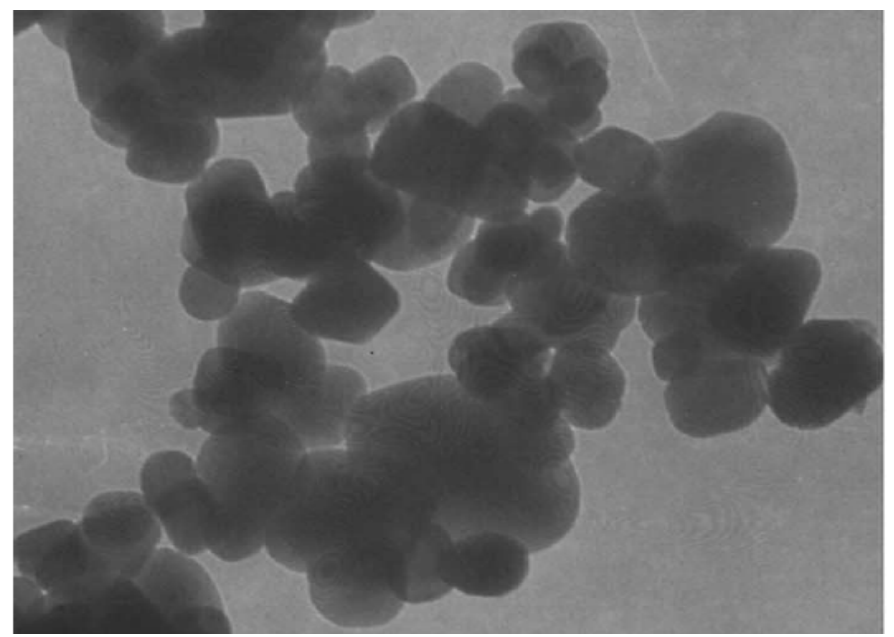

Fig 1.TEM micrograph of $\mathrm{TiO}_{2}$

A 120 W UV lamp with irradiation $247 \mathrm{~nm}$ wave lenght inside a quartz jacket was submerged in the reactor to provide better irradiation of water samples. This reactor was operated continuously, and stirred by use of a simple magnetic stirrer. The schematic diagram 
of the reactor used in the experiment is shown in Fig 2. The experiments are conducted in the inner part ( glass reactor) and the outer part designed to act as a cooling bath for circulating cold water and maintaining the temperature at $20^{\circ} \mathrm{C}$. A $100 \mathrm{mg} / \mathrm{L}$ arsenic stock solution was prepared from $\mathrm{Na}_{2} \mathrm{HASO}_{4} .7 \mathrm{H}_{2} \mathrm{O}$. The arsenic solutions, used in this study with 5,15 and 20 $\mathrm{mg} / \mathrm{L}$ concentration, were obtained by diluting the stock solution to desired concentration in distilled water. The effects of other parameters including initial $\mathrm{pH}$ (3, 7 and 11), arsenic concentration, amount of titanium oxide nanoparticles $(0.25,0.5,0.75,1$ and $1.5 \mathrm{mg} / \mathrm{L})$ and reaction time were investigated. The batch adsorption experiments conducted for each concentration with different amounts of $\mathrm{TiO}_{2}$ nano particles. The photocatalytic reaction then undertaken by switching on UV lamp. All the experiments were done by maintaining one factor constant and changing other parameters. Samples then centrifuged (4000 rpm) and the amount of arsenic was detected by Hatch arsenic kits (Product \#2822800) which its validity was approved previously (Edwards et al., 1998). The solutions $\mathrm{pH}$ was controlled by addition of $\mathrm{NaOH}$ or $\mathrm{HCl}$. The $\mathrm{pH}$ of solution was measured using $\mathrm{pH}$ meter (Metrohm E520).

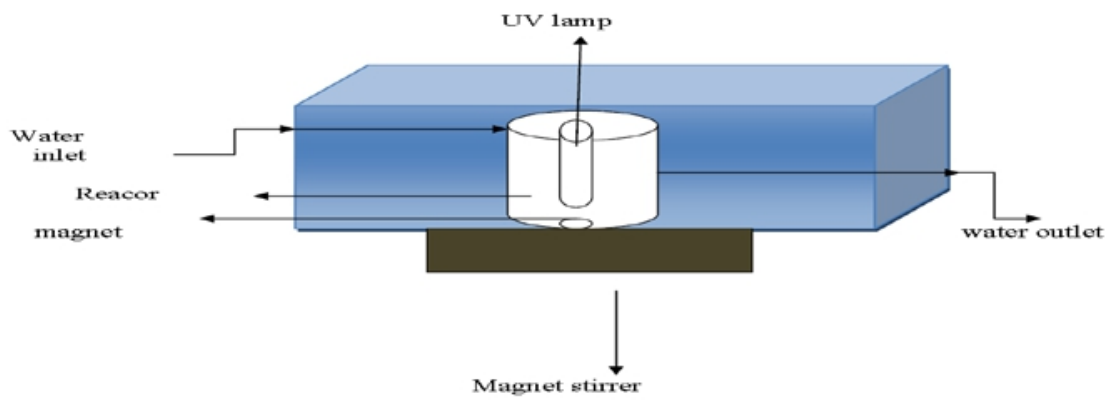

Fig 2. Shematic representation of photocatalytic reactor

\section{Results and discussion}

\section{Effects of initial $\mathrm{TiO}_{2}$ concentration and adsorption time}

The effects of different initial $\mathrm{TiO}_{2}$ nanoparticles on arsenic removal were investigated at arsenic initial concentration of $15 \mathrm{mg} / \mathrm{L}$ and $\mathrm{pH}$ 7. The results obtained were shown in Fig 3. As shown in figure 3 as the adsorbent concentrations increased, arsenic removal enhanced. The initial sharp rise within $20 \mathrm{~min}$ of adsorption indicates the availability of readily accessible sites for adsorption. However, after 25 min a plateau is reached, indicating virtually no more sites remain available for further arsenic adsorption. Moreover, Arsenic removal increased from $35 \%$ to $68 \%$ when $\mathrm{TiO}_{2}$ nanoparticles concentration increased from 0.25 to $1 \mathrm{mg} / \mathrm{L}$. No hefty removal in arsenic observed when adsorbent dosage increased to $1.5 \mathrm{mg} / \mathrm{L}$. Therefore, This value was chosen for the conduction of photocatalytic experiments.

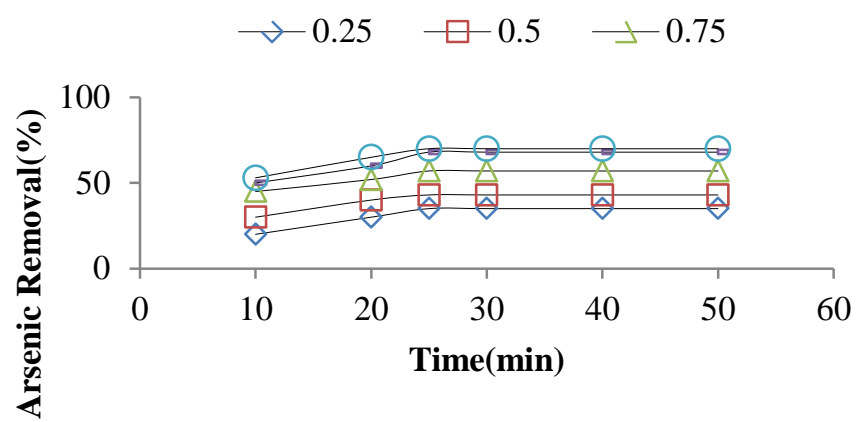

Fig 3. Effects of $\mathrm{TiO}_{2}$ concentrations on arsenic adsorption 


\section{Effects of initial $\mathrm{pH}$ in photocatalytic reaction}

The effects of various $\mathrm{pH}$ were investigated and the results are shown in Fig 4. The experiment conducted with arsenic initial concentration of $15 \mathrm{mg} / \mathrm{L}$ and $1 \mathrm{mg} / \mathrm{L}$ of $\mathrm{TiO}_{2}$ nanoparticles. As shown in Fig 4 maximum removal of arsenic (95\%) was observed in pH 11. In $\mathrm{pH}=3$ removal efficiencies decreased. The following shows Arsenic Photocatalytic oxidation with $\mathrm{TiO}_{2}$ (Aceituno et al., 2002).

$\mathrm{TiO}_{2}+\mathrm{UV} \longrightarrow \mathrm{e}^{-}+\mathrm{h}^{+}$(irradiation of the photocatalytic surface leads to an excited electron $\left(\mathrm{e}^{-}\right)$and electron gap $\left(\mathrm{h}^{+}\right)$

$\mathrm{Ti}(\mathrm{IV})+\mathrm{H}_{2} \mathrm{O} \rightleftarrows \mathrm{Ti}(\mathrm{IV})-\mathrm{H}_{2} \mathrm{O}$ (water absorbs onto the catalyst surface)

$\mathrm{Ti}(\mathrm{IV})-\mathrm{H}_{2} \mathrm{O}+\mathrm{h}^{+} \rightleftarrows \mathrm{Ti}(\mathrm{IV}) \cdot-\mathrm{OH}+\mathrm{H}^{+}$the highly reactive electron gap will react with water

The zero charge point for $\mathrm{TiO}_{2}$ particles depending on their anatas form various from 5 to 7. If the mentioned $\mathrm{pH}$ is higher or lower, the $\mathrm{TiO}_{2}$ surface charge becomes negative and positive, respectively. As a result, $\mathrm{TiO}_{2}$ surface in basic conditions has negative charge and arsenic absorption on the negative surface of $\mathrm{TiO}_{2}$ is easier in basic $\mathrm{pH}$. Decreasing $\mathrm{pH}$ gradually increases the electrostatic repulsion between $\mathrm{TiO}_{2}$ surface and arsenic, which is positively charged at $\mathrm{pH}$ below 5 (Hidaka et al., 2004).

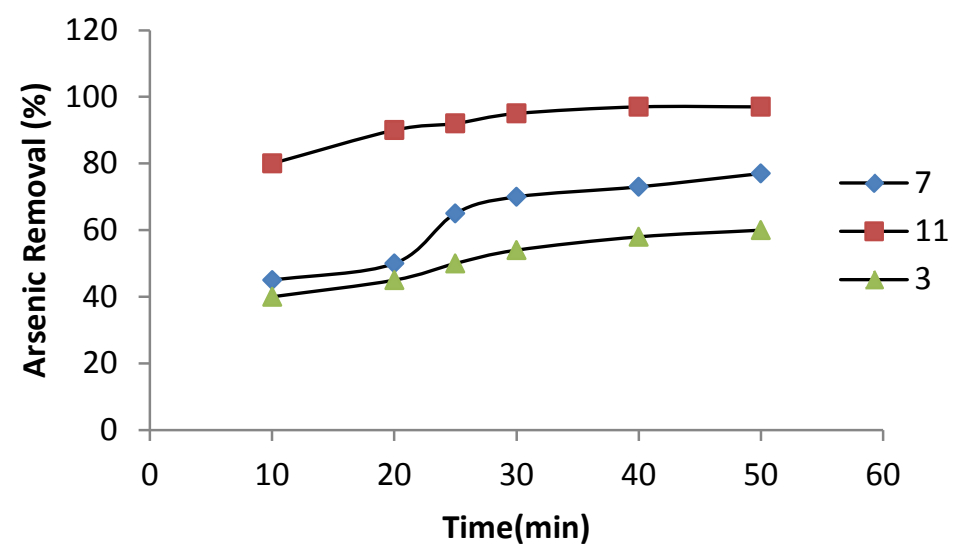

Fig 4. Effect of $\mathrm{pH}$ in photocatalytic reaction

\section{Effects of initial arsenic concentration}

The effects of initial arsenic concentration of its removal in $\mathrm{pH} 11$ is shown in Fig5. It is shown that initial arsenic concentration strongly affected its removal. The removal observed decreased as initial arsenic concentration gradually increased from 5 to $20 \mathrm{mg} / \mathrm{L}$. When the amount of arsenic is small the photogenerated electrons efficiently transfer to $\mathrm{TiO}_{2}$, as the result better separation of electrons and holes would be achieved . These electrons could react with adsorbed oxygen molecular or surface $\mathrm{Ti}^{4+}$ to form reactive species $\mathrm{O}_{2}{ }^{0-}$ and reactive center surface $\mathrm{Ti}^{3+}$, respectively. This suggested that the recombination was slowed and the generation of $\mathrm{O}_{2}{ }^{0-}$ and surface $\mathrm{Ti}^{3+}$ was accelerated. In this situation the yield of $\mathrm{OH}^{0}$ would also be increased. However higher amount of arsenic lead to its deposition which would cover more $\mathrm{TiO}_{2}$ surface and hinder the contact between $\mathrm{TiO}_{2}$ and arsenic, which would increase diffuse distance and decrease the amount of received photons. Furthermore, As the radical densities were equal in all the solutions, a solution with low arsenic concentration with the same hydroxyl radical rate, would have higher transformation rate in comparison to solutions with higher density rates (Lopez et al., 2006).

The obtained results indicate that the $\mathrm{UV} / \mathrm{TiO}_{2}$ process is robust to remove arsenic by $1 \mathrm{mg} / \mathrm{L} \mathrm{TiO}_{2}$ within $25 \mathrm{~min}$. It is also proved in this research that arsenic removal using this 
process follows the first order kinetics. Moreover, results showed that arsenic was better in basic $\mathrm{pH}$. Removal enhanced in lower concentration of arsenic as in higher concentration it deposited on UV lamps which subsequently reduced UV penetration on $\mathrm{TiO}_{2}$ area.

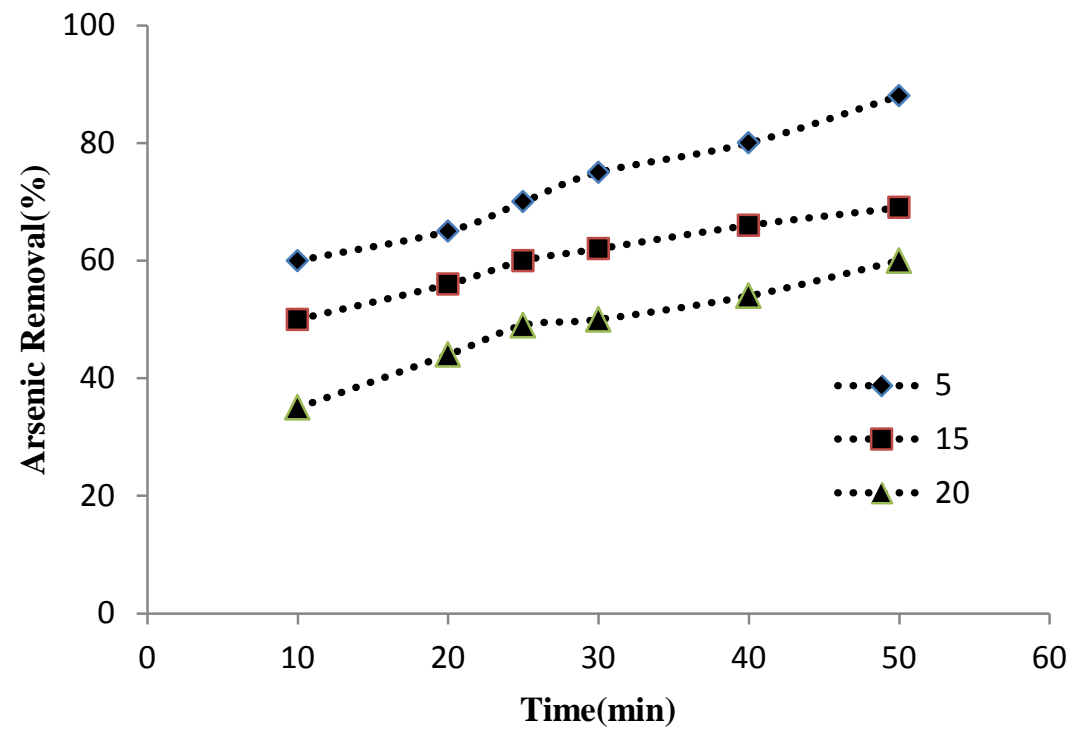

Fig 5. Effect of arsenic initial concentration in photocatalytic reaction

\section{References:}

Aceituno M, Stalikas CD, Lunar L, Rubio S, Pérez-Bendito D. H2O2/TiO2 photocatalytic oxidation of metol, Identification of intermediates and reaction pathways. Water Res.2002; 36: 3582-359.

Awual M, Urata S, Jyo A, Tamada M, Katakai A. Arsenate removal from water by a weakbase anion exchange fibrous adsorbent. Water Res. 2008; 42(3): 689-696.

Baba Y, Ohguma K, Kawano K. Highly selective adsorption resins, Synthesis of chitosan derivatives and their adsorption properties for nitrate anion. Chem J. 1999; 7: 471- 472.

Basu A, Mahata J, Gupta S, Giri AK. Genetic toxicology of a paradoxical human carcinogen, arsenic: a review. Mutat Res-Rev Mutat.2010; 488(2): 171-194.

Bellack E. Arsenic removal from potable water. J Am Water Works Ass. 1971; 63(7): 454458.

Blssen M, Frimmel FH. Arsenic: a review. Part I: Occurrence, toxicity, speciation, mobility. Acta Hydroch Hydrob. 2003; 31(1): 9-18.

Chen PY, Wilkie JA. Arsenic removal from drinking water during coagulation. J Enviro Eng. 1997; 123: 800-805.

Choong TSY, Chuah TG, Robiah Y, Gregory Koay FL, Azni I. Arsenic toxicity, health hazards and removal techniques from water: an overview. Desalination. 2007; 217(1-3):139166.

Edwards, M. Patel, S. McNeill, L. Chen, H. Frey, M. Eaton, AD. Antweiler, RC. Taylor, HE. (1998). Considerations in As analysis and speciation. J Am Water Works Ass, 90(3), 103113.

EPA US. National Primary Drinking Water Regulations; Arsenic and Clarifications to Compliance and New Source Contaminants Monitoring; Final Rule. Federal Register.2001; 6: 6976-7066.

Hidaka H, Koike T, Kurihara T, Serpone N. Dynamics and mechanistic features in the photocatalyzed oxidation of disulfonated anionic surfactants on the surface of UV-irradiated titania nanoparticles. New J. of Chemistry. 2004; 28: 1100-1106.

Lopez JL, Garcia Einshlag FS, Gonzles AL, Cappearelli E, Oliversos TM, Braun AM. 
Hydroxyl radical photodegradation of 4-Chloro-3,5-Dinitrobenzoic acid in aqueous solution. J. Photochem. Photobio. A: Chemistry. 2006; 137: 177-184.

Mandal BK, Suzuki KT. Arsenic round the world: a review. Talanta. 2002; 58(1): 201-235. Sorg TJ. Treatment technology to meet the interim primary drinking water regulations for inorganics: part 4. J Am Water Works Ass. 1997; 71(8): 454-466.

Waypa JJ, Elimelech M, Hering JG. Arsenic removal by RO and NF membranes. J Am Water Works Ass. 1997; 89(10): 102-114. 